\title{
GAMMA-AMINO BUTYRIC ACID METABOLISM UNDER HIGH TEMPERATURE STRESS IN TWO LICHEN SPECIES
}

\author{
Cekic, F. O. ${ }^{1}$ - Goren-Saglam, N. ${ }^{2 *}-$ Torun, H. ${ }^{3}-$ Yigit, E. ${ }^{4}-$ UnAL, D. ${ }^{5,6}$ \\ ${ }^{I}$ Department of Biology, Faculty of Science and Letters, Aksaray University, Aksaray, Turkey \\ ${ }^{2}$ Department of Biology, Faculty of Science, Istanbul University, Istanbul, Turkey \\ ${ }^{3}$ Department of Biosystem Engineering, Faculty of Agriculture and Natural Science, \\ University of Düzce, Düzce, Turkey \\ ${ }^{4}$ Department of Biology, Faculty of Science and Letter, University of İnönü, Malatya, Turkey \\ ${ }^{5}$ Department of Molecular Biology and Genetic, Faculty of Science and Letter, University of \\ Bilecik S. E., Bilecik, Turkey \\ ${ }^{6}$ Biotechnology Application and Research Center, University of Bilecik S. E., Bilecik, Turkey \\ *Corresponding author \\ e-mail: gorenn@istanbul.edu.tr; phone: +90-212-455-5700; fax: +90-212-522-6562
}

(Received $6^{\text {th }}$ Jun 2018; accepted $14^{\text {th }}$ Aug 2018)

\begin{abstract}
High temperature stress is a major environmental stress factor for all photosynthetic organisms. Some lichen species could have the ability of tolerance against global warming. In the present study, we investigated the effects of high temperature on GABA metabolism in two different lichen species Evernia prunastri and Usnea sp.. Evernia and Usnea sp. were collected from unpolluted locations in Bilecik, TURKEY. Evernia and Usnea sp. were kept at $45^{\circ} \mathrm{C}$ for 0,24 and 48 h. We analyzed GABA content, glutamate dehydrogenase (GDH) and glutamate decarboxylase (GAD) activities and also chlorophyll and MDA contents in the thalli of the lichens. The chlorophyll degradation and lipid peroxidation data indicated that E. prunastri thalli showed tolerance to high temperature while Usnea sp. thalli were found to be sensitive under these conditions. GABA content was enhanced by high temperature stress in E. prutastri thalli, while GAD and GDH activities were decreased. According to our results, we can suggest that GABA accumulation in lichen thalli could occur via different metabolic pathways.

Keywords: Evernia, GABA, glutamate decarboxylase, glutamate dehydogenase, high temperature, Usnea
\end{abstract}

Abbreviations: GABA: gamma-amino butyric acid; GAD: glutamate decarboxylase; GDH: glutamate dehydrogenase; MDA: malondialdehyde

\section{Introduction}

Global warming is one of the most serious problems for all organisms, populations, and ecological communities (Walther et al., 2002; Liu et al., 2003; Pisani et al., 2007). Climatic changes can negatively influence photosynthetic organisms; disrupt cellular homeostasis, and alter their morphology, biochemical structure, and physiology (Karl et al., 2007; Bita and Greats, 2013). High temperature stress can cause membrane damages, inhibit protein and carbohydrate metabolisms via inactivation of the enzymes in mitochondria and chloroplasts (Bita and Greats, 2013).

Gamma-amino butyric acid (GABA) plays different roles in plant metabolism including carbon-nitrogen metabolism, energy balance, signaling and development. It is found in a wide range of organisms including plants, algae and lichens (Bouché and Fromm, 2004; 
Yolcu et al., 2013). GABA probably plays a dual role as both a signaling molecule and a metabolite (Fait et al., 2008). GABA is mainly synthesized in metabolic pathway known as GABA shunt. It plays a major role in primary $\mathrm{C} / \mathrm{N}$ metabolism. GABA shunt includes three main enzymes; cytosolic enzyme glutamate decarboxylase (GAD; EC 4.1.1.15), the mitochondrial enzymes GABA transaminase (GABA-T; EC 2.6.1.19), and succinic semialdehyde dehydrogenase (SSADH; EC 1.2.1.16). Enhancement in GABA content under various stress conditions such as drought, chilling, salt, heavy metal stresses was reported by several researchers (Bor et al., 2009; Al-Quraan et al., 2013; Wang et al., 2016). Previous studies demonstrated that GABA shunt pathway plays an important role in the alleviation of oxidative stress caused by high temperature stress (Cao et al., 2013; Nayyar et al., 2014).

Lichens are poikilohydric organisms and highly adapted to osmotic dehydration (Hájek et al., 2006). Most of the species have ability of tolerance against global warming and can live in the range of $35-46{ }^{\circ} \mathrm{C}$ and survive even at $70{ }^{\circ} \mathrm{C}$ (Pisani et al., 2007; Dyakov et al., 2015), although some air-dried lichen species are being sensitive to high temperature stress (Van Herk et al., 2002). Similarly, in higher plants, high temperature could have an effect on the growth and physiological process of the lichens (Pissani et al., 2007). Previously studies demonstrated that increasing temperature caused to a reduction in chlorophyll content and directly or indirectly altered the synthesis of lichen substances (Bjerke et al., 2003). In the literature, there are very limited studies on the heat tolerance or stress, and physiological mechanisms of high temperature tolerance are not fully known in lichens. Moreover, the role of GABA metabolic pathway under high temperature conditions is not clearly elucidated yet. In the present study, our aim was to determine the role of GABA shunt under high temperature conditions. To find out the answers of these questions, we showed that the alteration of GABA accumulation, and activities of GAD and GDH enzymes in different lichen species; E. prunastri and Usnea sp. under high temperature.

\section{Materials and methods}

\section{Materials}

The lichen species, E. prunastri and Usnea sp. were collected from unpolluted locations from Bilecik Center Forest, Turkey (N 40 11.526', E 029 57.962') at February 2017. 90 individual samples were transferred to the laboratory in the plastic bags, cleaned from impurities, and washed three times for $5 \mathrm{~s}$ with distilled water to remove dust from the surface. All lichen species were transferred to petri dishes and incubated in a growth chamber under $100 \mu \mathrm{mol} \mathrm{m} \mathrm{m}^{-2} \mathrm{~s}^{-1}$ light intensity and 16:8 light/dark cycle at $23 \pm 2{ }^{\circ} \mathrm{C}$ and humidity was $\% 38$ for $48 \mathrm{~h}$ (Hall et al., 2002). Lichens were sprayed with distilled water once a day according to Calatayud et al. (1997). After laboratory adaptation, experimental conditions were designed. Lichen thalli was used as a control after the incubation for $48 \mathrm{~h}$ in normal growth conditions (as seen in Table 1; 0 h data).

For temperature experiments, 30 individual thalli of E. prunastri and Usnea sp. in petri dishes were kept for 0,24 and $48 \mathrm{~h}$ in an incubator $100 \mu \mathrm{mol} \mathrm{m} \mathrm{m}^{-2} \mathrm{~s}^{-1}$ light intensity and 16:8 light/dark cycle at $45 \pm 2{ }^{\circ} \mathrm{C}$ and likewise watered once a day. Heat stress temperature was chosen according to Pissani et al (2007) studies. The data presented in this study are the averages of three independent experiments. 
Table 1. Chlorophyll $a$, and $b$ content and Chlorophyll $a / b$ ratio in thalli of E. prunastri and Usnea sp. under heat stress for 0 (as a control), 24 and $48 \mathrm{~h}$

\begin{tabular}{|c|c|c|c|c|c|c|c|}
\hline \multirow[b]{2}{*}{ Groups } & \multirow[b]{2}{*}{$\mathbf{n}$} & \multicolumn{3}{|c|}{ E. prunastri } & \multicolumn{3}{|c|}{ Usnea sp. } \\
\hline & & $\begin{array}{c}\text { Chla } \\
(\mu \mathrm{g} / \mathrm{mg} \text { fw })\end{array}$ & $\begin{array}{c}\text { Chlb } \\
(\mu \mathrm{g} / \mathrm{mg} \text { fw })\end{array}$ & $\begin{array}{c}\text { Chla/b } \\
(\mu \mathrm{g} / \mathrm{mg} \mathrm{fw})\end{array}$ & $\begin{array}{c}\text { Chla } \\
(\mu \mathrm{g} / \mathrm{mg} \text { fw })\end{array}$ & $\begin{array}{c}\text { Chl } b \\
(\mu \mathrm{g} / \mathrm{mg} \mathrm{fw})\end{array}$ & $\begin{array}{c}\text { Chla/b } \\
(\mu \mathrm{g} / \mathrm{mg} \text { fw) }\end{array}$ \\
\hline $0 \mathrm{~h}$ & 3 & $1.385 \pm 0.11$ & $0.444 \pm 0.09$ & $3.12 \pm 0.03$ & $1.456 \pm 0.33$ & $0.455 \pm 0.13$ & $3.20 \pm 0.03$ \\
\hline $24 \mathrm{~h}$ & 3 & $1.132 \pm 0.16$ & $0.481 \pm 0.04$ & $2.39 \pm 0.01$ & $0.884 \pm 0.76$ & $0.424 \pm 0.40$ & $2.09 \pm 0.02$ \\
\hline $48 \mathrm{~h}$ & 3 & $0.867 \pm 0.20$ & $0.308 \pm 0.03$ & $2.87 \pm 0.13$ & $1.089 \pm 0.19$ & $0.713 \pm 0.06$ & $1.49 \pm 0.01$ \\
\hline p-value & & $<0.0001$ & $<0.0001$ & 0.0005 & 0.0003 & 0.0002 & $<0.0001$ \\
\hline F probability & & 802.63 & 291085.45 & 92.12 & 115.73 & 133.25 & 6600.25 \\
\hline
\end{tabular}

\section{Chlorophyll content analysis}

Chlorophyll analysis was determined using the method described by Wellburn (1994). Approximately $20 \mathrm{mg}$ of thalli were extracted in the dark for $1 \mathrm{~h}$ at $65^{\circ} \mathrm{C}$ in $3.0 \mathrm{~mL}$ of dimethyl sulfoxide (DMSO) in the presence of polyvinylpolyrrolidone to minimise chlorophyll degradation. The absorbances of the extracts were measured using a UV-visible spectrophotometer (Perkin Elmer). For the chlorophyll analysis, measurements were taken at the wavelengths 665.1 and $649.1 \mathrm{~nm}$.

\section{Lipid peroxidation}

Formation of malondialdehyde (MDA) was evaluated as an indicator of lipid peroxidation. The determination of MDA was performed by the thiobarbituric acid reactive substances method (Heath and Packer, 1968). The absorbance differences between 532 and $600 \mathrm{~nm}$ was used to calculate MDA formation as a by-product of lipid peroxidation.

\section{GABA analysis}

GABA content was detected by HPLC (Agilent 1200) according to Bor et al. (2009). $0.1 \mathrm{~g}$ of lichen samples (E. prunastri and Usnea sp. were homogenized in $5 \mathrm{~mL}$ solution of water:chloroform:methanol $(3: 5: 12 \mathrm{v} / \mathrm{v} / \mathrm{v})$, and centrifuged at $4{ }^{\circ} \mathrm{C}$ for $10 \mathrm{~min}$. The supernatant was dried. The dried samples were dissolved in water, Borax buffer $(\mathrm{pH}$ 8.0) and 2-hydroxynaphthaldehyde $\left(0.3 \%\right.$ in methanol) and heated at $80{ }^{\circ} \mathrm{C}$ for $30 \mathrm{~min}$. The samples were separated by reversed-phase column Supelco LC18 $\left(250 \times 4.6 \mathrm{~mm}^{2}\right.$, $5 \mu \mathrm{m})$ at $330 \mathrm{~nm}$ with a mobile phase of methanol:water $(62: 38 \mathrm{v} / \mathrm{v})$. The injection volume was $5 \mu \mathrm{L}$. GABA content was calculated according to the peak areas of GABA standarts.

\section{GAD and GDH enzyme analysis}

GDH activity was measured according to Akihiro et al. (2008) and Yolcu et al. (2013). The extracts were mixed with the assay mixture containing $50 \mathrm{mM}\left(\mathrm{NH}_{4}\right)_{2} \mathrm{SO}_{4}$, $13 \mathrm{mM} \alpha$-ketoglutarate, $0.25 \mathrm{mM}$ NADPH and $1 \mathrm{mM} \mathrm{CaCl}_{2}$ in $100 \mathrm{mM}$ Tris- $\mathrm{HCl}$ buffer (pH 8.0). GDH activity was measured according to the absorbance differences at $340 \mathrm{~nm}$ and expressed as micromoles per minute per gram fresh weight $(\mathrm{FW})$. 
GAD activity was assayed according to Bartyzel et al. (2003) and Yolcu et al. (2013). $100 \mu \mathrm{L}$ of sample was mixed with reaction mixture containing $3 \mathrm{mM} \mathrm{L}$ glutamate, $20 \mu \mathrm{M}$ pyridoxal phosphate and $50 \mathrm{mM}$ potassium phosphate $(\mathrm{pH} 5.8)$ and incubated at $30{ }^{\circ} \mathrm{C}$ for $1 \mathrm{~h}$ for the decarboxylation process. $\mathrm{HCl}(0.5 \mathrm{M})$ was added to the mixture to stop the reaction. The samples were derivatized with $0.35 \%(\mathrm{w} / \mathrm{v})$ ninhydrin solution. GAD activity was determined spectrophotometrically by comparing with the standard GABA values, and calculated as micromoles per minute per gram.

\section{Statistics}

Statistical analysis was performed with one-way analysis of variance (ANOVA) and Student's t-test followed by posthoc Tukey test as appropriate (SPSS for Windows version 11.0). The critical values for statistical significance was $p<0.05$ and 0.01 .

\section{Results}

Malondialdehyde (MDA) is often used as an indicator of oxidative damage at the cellular level. Figure 1 shows the MDA content of thalli after exposure to high temperature for 0,24 and $48 \mathrm{~h}$. In E. prunastri thallus, MDA content was not significantly changed at $24 \mathrm{~h}$, but the MDA content significantly increased $(\mathrm{p}<0.001)$ at $48 \mathrm{~h}$ under high temperature (Fig. 1). In Usnea sp. thallus, the MDA content significantly increased at $24 \mathrm{~h}$ and $48 \mathrm{~h}$.

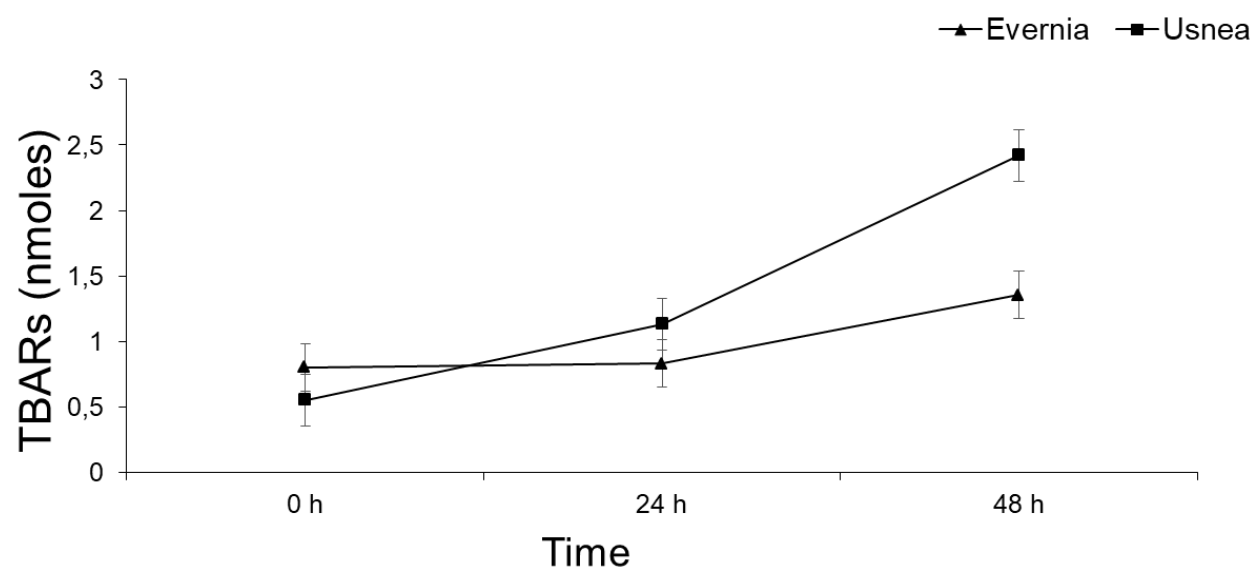

Figure 1. Lipid peroxidation of different two lichen species under heat stress $\left(45^{\circ} \mathrm{C}\right)$ for $0 \mathrm{~h}$, $24 \mathrm{~h}$ and $48 \mathrm{~h}$

The results of this study showed that the chlorophyll $a$ content was significantly $(\mathrm{p}<0.001)$ altered by high temperature treatment at $24 \mathrm{~h}$ and $48 \mathrm{~h}$ between lichen species. In $E$. prunastri thalli, however the chlorophyll $a$ content gradually decreased at 24 and $48 \mathrm{~h}$, chlorophyll $b$ content was not significantly changed at $24 \mathrm{~h}$ (Table 1). The chlorophyll $a / b$ ratio in the thallus of E. prunastri showed differences under 24 and $48 \mathrm{~h}$ exposures. In Usnea sp. The chlorophyll a content was significantly decreased at 24 and $48 \mathrm{~h}$ when compared to the control groups $(\mathrm{p}<0.001)(0 \mathrm{~h}$, as seen in Table 1$)$. The content of chlorophyll $b$ increased significantly under $48 \mathrm{~h}$ high temperature exposure. The chlorophyll $a / b$ ratio decreased significantly after $24 \mathrm{~h}$ and $48 \mathrm{~h}$ exposures in Usnea sp. (Table 1). 
As shown in Figure 2, GABA was enhanced under heat especially by time exposures. The highest increase was determined in E. prunastri under $48 \mathrm{~h}$ heat treatment. The lowest increase was detected in Usnea sp. However, we did not find any significant increase in the GABA content under $24 \mathrm{~h}$ treatment in Usnea sp.

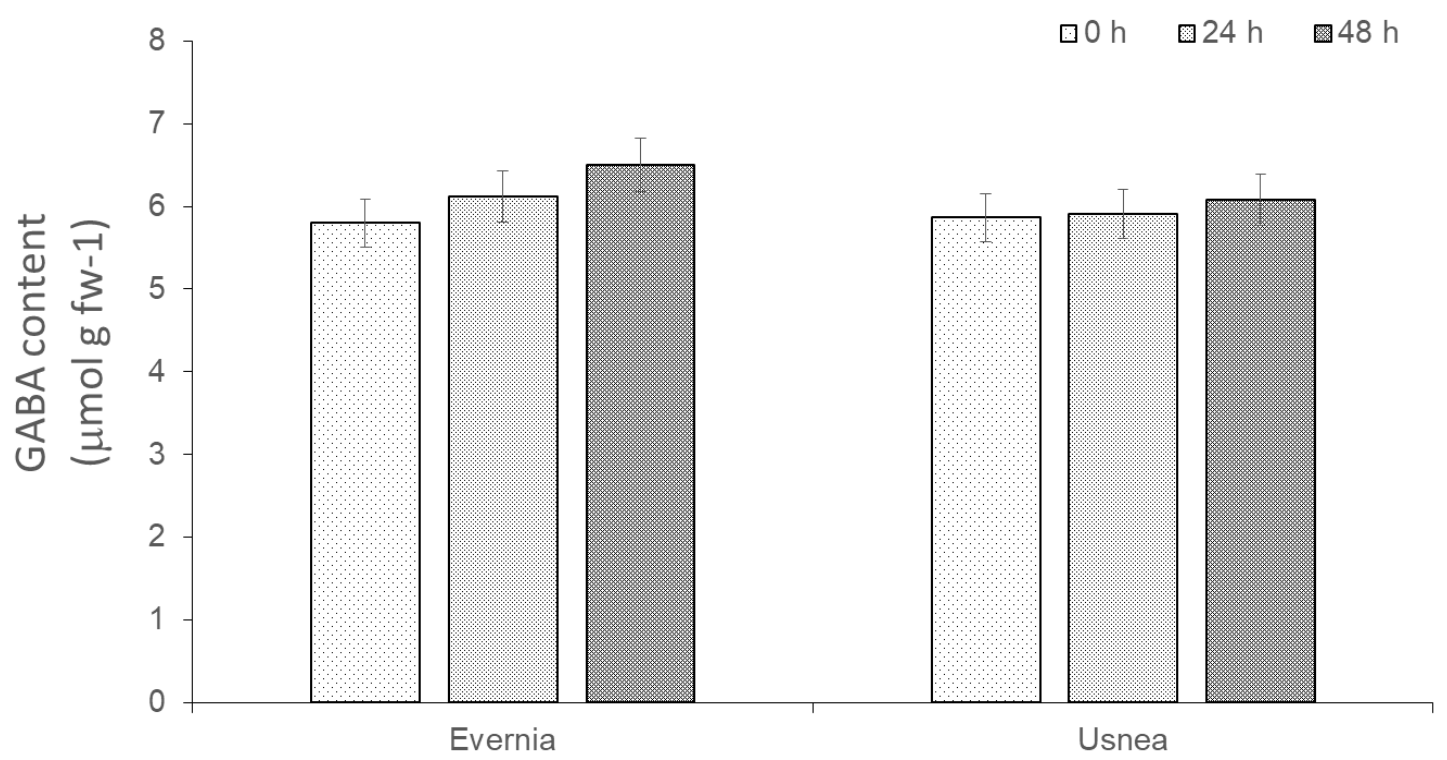

Figure 2. GABA content of different two lichen species under heat stress $\left(45^{\circ} \mathrm{C}\right)$ for $0 \mathrm{~h}, 24 \mathrm{~h}$ and $48 \mathrm{~h}$

GAD activity was significantly decreased by heat treatments in E. prunastri when compared to the control group (Fig. 3). However, it was significantly increased by $24 \mathrm{~h}$ heat treatment in Usnea sp. as compared to the control group ( $<<0.05) .48 \mathrm{~h}$ heat treatment did cause a decline in GAD activity in all of the species.

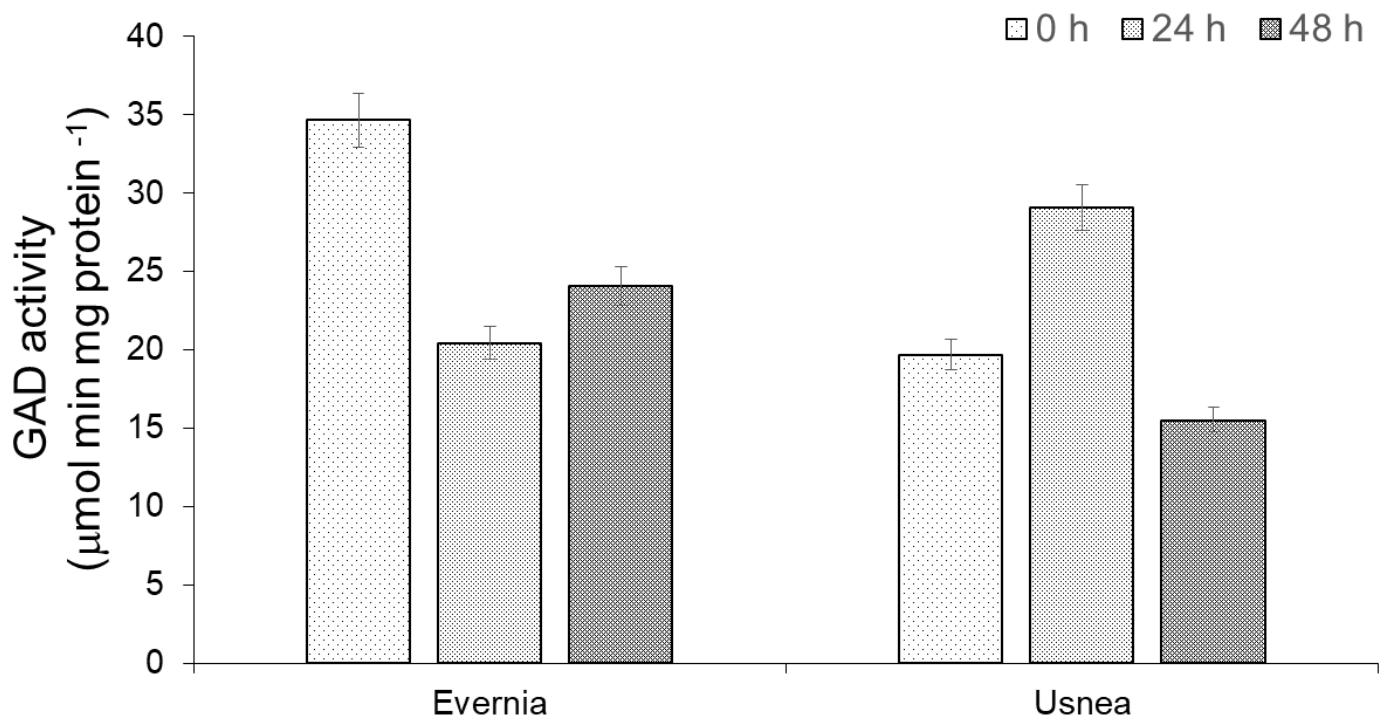

Figure 3. GAD enzyme activities of different two lichen species under heat stress $\left(45^{\circ} \mathrm{C}\right)$ for $O \mathrm{~h}, 24 \mathrm{~h}$ and $48 \mathrm{~h}$ 
GDH activity was not significantly changed in both lichen species as compared to their control groups. However, GDH activity was increased under $24 \mathrm{~h}$ heat treatment in E. prunastri when compared to the control group (Fig. 4). In addition, GDH activity was significantly increased when compared to $48 \mathrm{~h}$ heat teratment in the thalli of Usnea $\mathrm{sp}(\mathrm{p}<0.05)$.

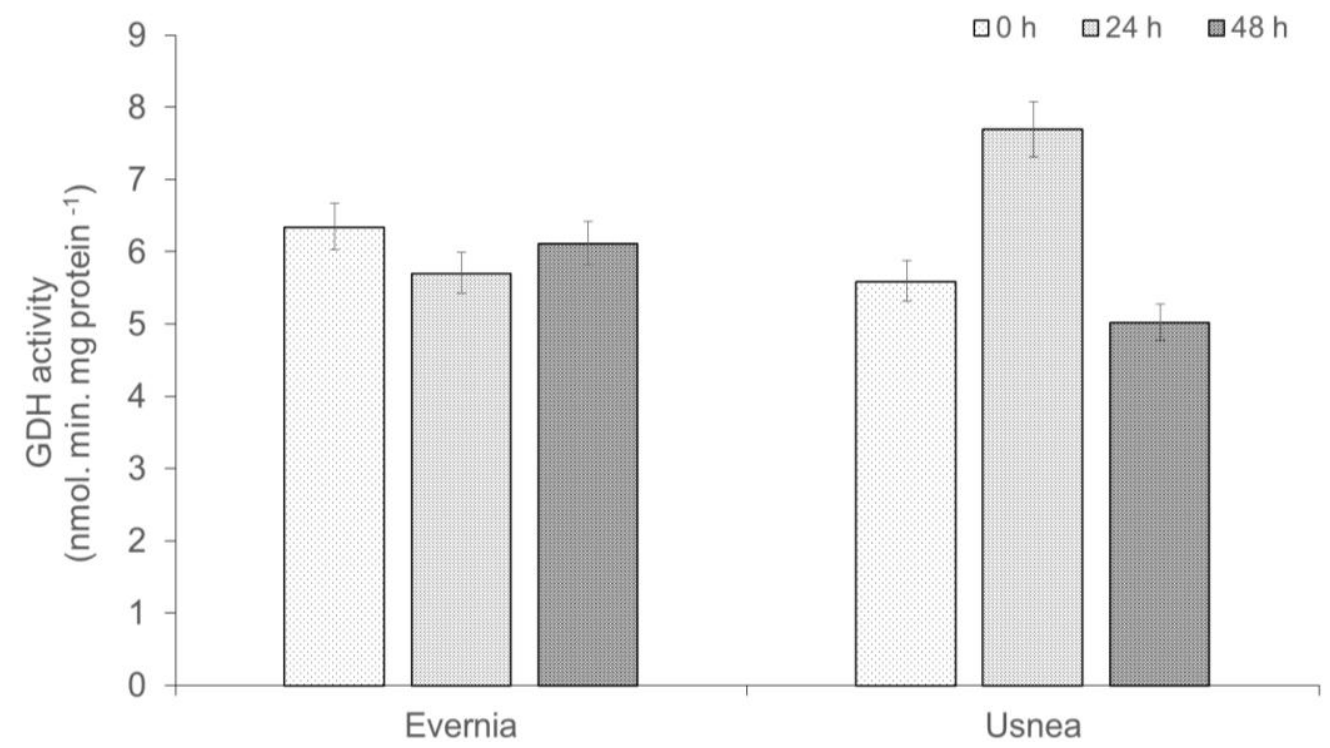

Figure 4. GDH enzyme activities of different two lichen species under heat stress $\left(45^{\circ} \mathrm{C}\right)$ for $0 \mathrm{~h}, 24 \mathrm{~h}$ and $48 \mathrm{~h}$

\section{Discussion}

High temperature can induce oxidative stress via ROS production and lead can cause loss of cellular homeostasis in the photosynthetic organisms (Liu et al., 2003; Almeselmani et al., 2006). Oxidative stress also causes destruction of cell membranes via lipid peroxidation (Almeselmani et al., 2006). Malondialdehyde, MDA, is produced naturally as a result of lipid peroxidation and is often used as an indicator of oxidative damage at the cellular level (Mittler, 2002). Previous studies reported that high membrane damage occurs at higher temperatures and this could cause to the loss of structural organization of the membranes (Liu et al., 2003; Almeselmani et al., 2009; Hafmann, 2012). In our study, lipid peroxidation rate increased in Usnea sp., while MDA content did not significantly change in E. prunastri thalli at $24 \mathrm{~h}$ (Fig. 1). Our results indicate that thallus of $E$. prunastri could be more tolerant to heat stress.

Chlorophyll content is an important indicator for the photosynthetic process. It is also very sensitive to stress-initiated oxidative stress such as photo-oxidation (Chettri et al., 1998). Chlorophyll $b$ is formed from chlorophyll $a$ by the oxidation of the methyl group on the ring II to the aldehyde group (Chettri et al., 1998), and the ratio of chlorophyll $a / b$ is more sensitive to the modification than chlorophyll $a+b$. In green plants, the antenna size is determined by the amount of light-harvesting chlorophyll $a / b$ protein complex that is associated with the PSII (Takana and Takana, 2006). Conversion of chlorophyll $b$ to chlorophyll $a$ is the first step in chlorophyll degradation, as well as influencing chlorophyll a / b ratio (Chettri et al., 1998; Takana and Takana, 2006). Therefore, chlorophyll degradation is frequently used to identify the physiological 
conditions of the lichens (Chettri et al., 1998; Bačkor and Zetiková, 2003). Many lichen species could have tolerance to climate change and high temperature (Pisani et al., 2007). Pisani et al. (2007) showed that the content of photosynthetic pigments was not significantly changed at $40{ }^{\circ} \mathrm{C}$ for $24 \mathrm{~h}$ in E. prunastri. Similarly, in our study, chlorophyll degradation was not decreased in the range of 4-2 in E. prunastri thalli under high temperature stress (Table 1). However, the chl $a / b$ ratio significantly decreased in the thalli of Usnea sp. during 24 and $48 \mathrm{~h}$. Exposure of Usnea sp. to the temperature of $45^{\circ} \mathrm{C}$ had significantly negative effect on the content of photosynthetic pigments (Table 1). Our results indicated that E. prunastri has more tolerance capacity than Usnea sp. under high temperature stress.

GABA biosynthesis is enhanced via various stress conditions (Bor et al., 2009; AlQuraan et al., 2011; Paradisone et al., 2015), and GABA pathway could regulate the adaptation mechanisms (Al-Quraan and Al-Share, 2016). GABA is synthesized from glutamate by the activity of cytosolic GAD (Bouche et al., 2003). In higher plants, many researchers have suggested that GAD activity played a dominant role in the accumulation of GABA (Cao et al., 2012). Yolcu et al. (2013) also reported that GAD activity is highly correlated with high GABA levels. GDH is an enzyme found in the mitochondria that catalyzes the deamination of glutamate which is then converted to GABA by the action of GAD (Andersson and Rager, 2003; Forde and Lea, 2007). In higher plants, GABA accumulation can have a role in the tolerance under many environmental stress conditions (Nayyar et al., 2014). Previous studies also demonstrated that rapid accumulation of GABA in response to heat-stress (Bouche et al., 2004; Nayyar et al., 2014). In the present study, high GABA accumulation could decrease lipid peroxidation at $48 \mathrm{~h}$ with increasing lipid peroxidation rate at $48 \mathrm{~h}$ exposure in E. prunastri thalli (Figs. 1 and 2). Therefore, we can suggest that GABA could be a signal for high temperature tolerance.

Among lichens, Jager and Weigel (1978) reported that GABA is one of the predominant amino acids in the lichen $P$. furfuracea. Yolcu et al. (2013) also found that lowest GDH activity showed in P. furfuracea thalli as compared to higher plant species. In Usnea sp. under $24 \mathrm{~h}$ heat treatment, we can suggest that GABA could be synthesized by the activity of GAD via GABA pathway. However; under $48 \mathrm{~h}$ heat treatment GAD activity did not increase when compared to control group while GABA contents were enhanced under the same conditions (Fig. 3). In E. prunastri thalli, GDH and GAD enzymes activities did not show any relation with GABA accumulation under high temperature stress (Figs. 3 and 4). Numerous publications in higher plants link GABA metabolism with polyamine biosynthesis pathways, however there is not any information in lichens. GABA can also be synthesized via polyamine pathway by polyamine degradation or reduction (Moschou et al., 2008; Yolcu et al., 2013). Moreover, Wang et al. (2016) showed that the elevated chilling tolerance in NO-treated banana fruit may be attributed to enhanced accumulation of polyamines and GABA.

\section{Conclusion}

According to our results, we can suggest that GABA could be mainly synthesized via GAD activity during normal conditions in Evernia and Usnea, but in stress conditions, GABA can be synthesized via polyamine accumulation. However, further studies should be done to identify the effects of polyamine pathway on GABA metabolism in lichens both under normal and stress conditions. 
Author contributions. All authors conceived research. Dr. Dilek Unal designed the experimental framework and chlorophyll and lipid peroxidation analysis. Dr. Fazilet Ozlem Cekic performed GABA and enzyme analyses. Dr. Nihal Goren-Saglam, Dr. Emel Yigit and Dr. Hulya Torun participated the experimental analysis. Dr. Dilek Unal and Dr. Nihal Goren-Saglam drafted the manuscript. All authors have read and approved the manuscript.

\section{REFERENCES}

[1] Akihiro, T., Koike, S., Tani, R., Tominaga, T., Watanabe, S., Iijima, Y., Aoki, K., Shibata, D., Ashihara, H., Matsukura, C., Akama, K., Fujimura, T., Ezura, H. (2008): Biochemical mechanism on GABA accumulation during fruit development in tomato. Plant and Cell Physiology 49: 1378-1389.

[2] Al-Quraan, N. A., Locy, R. D., Singh, N. K. (2011): Implications of paraquat and hydrogen peroxide-induced oxidative stress treatments on the GABA shunt pathway in Arabidopsis thaliana calmodulin mutants. - Plant Biotechnology Reports 5: 225-234.

[3] Al-Quraan, N. A., Sartawe, F. A., Qaryouti, M. M. (2013): Characterization of $\gamma-$ aminobutyric acid metabolism and oxidative damage in wheat (Triticum aestivum L.) seedlings under salt and osmotic stress. - Journal of Plant Physiology 170: 1003-1009.

[4] Al-Quraan, N. A., Al-Share, A. T. (2016): Characterization of the $\gamma$-aminobutyric acid shunt pathway and oxidative damage in Arabidopsis thaliana pop 2 mutants under various abiotic stresses. - Biologia Plantarum 60: 132-138.

[5] Almeselmani, M., Deshmukh, P. S., Sairam, R. K., Kushwaha, S. R., Singh, T. P. (2006): Protective role of antioxidant enzymes under high temperature stress. - Plant Science 171: 382-388.

[6] Andersson, J. O., Roger, A. J. (2003): Evolution of GDH genes: evidence for lateral gene transfer within and between prokaryotes and eukaryotes. - BMC Evolutionary Biology 3: 14.

[7] Bačkor, M., Zetiková, J. (2003): Effects of copper, cobalt and mercury on the chlorophyll content of lichens Centraria islandica and Flavocetraria cucullata. - Journal of the Hattori Botanical Laboratory 93: 175-187.

[8] Bartyzel, I., Pelczar, K., Paszkowski, A. (2003): Functioning of the gammaaminobutyrate pathway in wheat seedlings affected by osmotis stress. - Biologia Plantarum 47: 221-225.

[9] Bita, C. E., Gerats, T. (2013): Plant tolerance to high temperature in a changing environment: scientific fundamentals and production of heat stress-tolerant crops. Frontiers in Plant Science 4: 273. DOI: 10.3389/fpls.2013.00273.

[10] Bjerke, J. A., Zielke, M., Solheim, B. (2003): Long-term impacts of simulated climatic change on secondary metabolism, thallus structure and nitrogen fixation activity in two cyanolichens from the Arctic. - New Phytologist 159: 361-367.

[11] Bor, M., Seckin, B., Ozgur, R., Yılmaz, O., Ozdemir, F., Turkan, I. (2009): Comparative effects of drought, salt, heavy metal and heat stresses on gamma-aminobutryric acid levels of sesame. - Acta Physiologia Plantarum 31: 655-659.

[12] Bouche, N., Fait, A., Bouchez, D., Moller, S. G., Fromm, H. (2003): Mitochondrial succinic-semialdehyde dehydrogenase of the gamma-aminobutyrate shunt is required to restrict levels of reactive oxygen intermediates in plants. - Proceedings of the National Academy of Sciences 100: 6843-6848.

[13] Bouche, N., Fromm, H. (2004): GABA in plants : just a metabolite? - Trends in Plant Science 9: 110-115.

[14] Calatayud, A., Deltoro, V. I., Barreno, E., de Valle-Tascon S (1997): Changes in in vivo chlorophyll fluorescence quenching in lichen thalli as a function of water content and suggestion of zeaxanthin-associated photoprotection. - Physiologia Plantarum 101: 93102. 
[15] Cao, J., Barbosa, J. M., Singh, N., Locy, R. D. (2013): GABA shunt mediates thermotolerance in Saccharomyces ceresiae by reducing reactive oxygen production. Yeast 30: 129-144.

[16] Chettri, M. K., Cook, C. M., Vardaka, E., Sawidis, T., Lanaras T (1998): The effect of $\mathrm{Cu}, \mathrm{Zn}$, and $\mathrm{Pb}$ on the chlorophyll content of lichens Cladonia convolute and Cladonia rangiformis. - Environmental and Experimental Botany 39: 1-10.

[17] Dyakov, M. Y., Insarova, I. D., Kharabadze, D. E., Ptushenko, V. V., Shtaer, O. V. (2015): Influence of extreme ambient temperatures and anaerobic conditions on Peltigera aphthosa (L.) Wild. viability. - Life Sciences in Space Research 7: 66-72.

[18] Fait, A., Fromm, H., Walter, D., Galili, G., Fernie, A. R. (2008): Highway or byway: the metabolic role of the GABA shunt in plants. - Trends in Plant Science 13: 14-9.

[19] Forde, B. G., Lea, P. J. (2007): Glutamate in plants: metabolism, regulation and signalling. - Journal of Experimental Botany 58: 2339-2358.

[20] Hall, R. S. B., Bornman, J. F., Björn, L. O. (2002): UV-induced changes in pigment content and light penetration in the fruticose lichen Cladonia arbuscular ssp. mitis. Journal of Photochemistry and Photobiology: Biology 66: 13-20.

[21] Hájek, J., Barták, M., Dubová, J. (2006): Inhibition of photosynthetic processes in foilose lichens induced by temperature and osmotic stress. - Biologia Plantarum 50: 624-634.

[22] Heath, R. L., Packer, L. (1968): Photoperoxidation in isolated chloroplast: 1. Kinetics and stoichiometry of fatty acid peroxidation. - Archives of Biochemistry and Biophysics 125: 189-198.

[23] Jager, H. J., Weigel, H. J. (1978): Amino acid metabolism in lichens. - Bryologist 81: 107-113.

[24] Karl, T. R., Kukla, G., Razuvayev, V. N., Changery, M. J., Quayle, R. G., Heim, R. R., Easterling, D. R., Kotak, S., Larkindale, J., Lee, U., von Koskull-Döring, P., Vierling, E., Scharf, K. D. (2007): Complexity of the heat stress response in plants. - Current Opinion Plant Biology 10: 310-316.

[25] Liu, Y., Cao, T, Glime, J. M. (2003): The Changes of membrane permeability of mosses under high temperature stress. - Bryologist 106: 53-60.

[26] Mittler, R. (2002): Oxidative stress, antioxidants and stress tolerance. - Trends in Plant Science 7: 405-410.

[27] Moschou, P. N., Paschalidis, K. A., Roubelakis-Angelakis, K. A. (2008): Plant polyamine catabolism: the start of the art. - Plant Signal Behaviour 3: 1061-1066.

[28] Nayyar, H., Kaur, R., Kaur, S, Singh R (2014): $\gamma$-aminobutyric acid (GABA) imparts partial protection from heat stress injury to rice seedlings by improving leaf turgor and upregulating osmoprotectants and antioxidants. - Journal of Plant Growth Regulation 33: 408-419.

[29] Paradisone, V., Barrameda-Medina, Y., Montesinos-Pereira, D., Romero, L., Esposito, S., Ruiz, J. M. (2015): Roles of some nitrogenous compounds protectors in the resistance to zinc toxicity in Lactuca sativa cv. Phillipus and Brassica oleracea cv. Bronco. - Acta Physiologia Plantarum 37: 1-8.

[30] Pisani, T., Paoli, L., Gaggi, C., Pirintsos, S. A., Loppi, S. (2007): Effects of high temperature on epiphytic lichens: Issues for consideration in a changing climate scenario. - Plant Biosystem 141: 164-169.

[31] Tanaka, A., Tanaka, R. (2006): Chlorophyll metabolism; a review. - Current Opinion Plant Biology 9: 248-255.

[32] Van Herk, C. M., Aptroot, A., van Dobben, H. F. (2002): Long-term monitoring in the Netherlands suggests that lichens respond to global warming. - Lichenologist 34: 141154.

[33] Walther, G. R., Post, E., Convey, P., Menzel, A., Parmesan, C., Beebee, T. J. C., Fromentin, J. M., Hoegh-Guldberg, O., Bairlein, F. (2002): Ecological responses to recent climate change. - Nature 416: 389-395. 
[34] Wang, Y., Luo, Z., Mao, L., Ying, T. (2016): Contribution of polyamines metabolism and GABA shunt to chilling tolerance induced by nitric axide in cold-stored banana fruit. Food Chemistry 197: 333-339.

[35] Wellburn, A. R. (1994): The spectral determination of chlorophylls a and b, as well as total carotenoids, using various solvents with spectrophotometers of different resolution. - Journal of Plant Physiology 144: 307-313.

[36] Yolcu, S., Ozdemir, F., Bor, M. (2013): Gamma-amino butyric acid, glutamate dehydrogenase and glutamate decarboxylase levels in phylogenetically divergent plants. Plant Systematics and Evolution 299: 403-412. 